\title{
Coping with large multi-level class in English language learning
}

\author{
Benny Kurnianto \\ Indonesia Civil Aviation Polytechnic \\ benny.kurnianto@ppicurug.ac.id \\ *) correspondence: benny.kurnianto@ppicurug.ac.id
}

\begin{abstract}
To improve students' English proficiency, Indonesian Civil Aviation Institute has placed TOEFL® preparation in the curriculum of study program. Nevertheless, the learning design was not common compared with similar program of TOEFL ${ }^{\circledR}$ preparation in another institution. ICAI put a single teacher in class consisted of 24 students with various skills. Consequently, the English teacher had to employ a strategy to cope with this large multilevel class. This qualitative research was conducted to analyze the teacher's strategy. Its purpose is to give enlightenment toward the conformity between learning design and learning objectives. A pre-test and post-test were given to a determined class and the grades were compared to see the fulfillment of the objective. An observation and note taking was undertaken during the learning process to explain the strategy. The result shows that the teacher occupy cooperative learning through flexible grouping to cope the class challenge. While the result shows $57 \%$ students in the class were able to gain 500 as minimum required score, it has implication in examining the learning design in broader context.
\end{abstract}

Keywords: classroom; multilevel; teacher-students ratio

\section{INTRODUCTION}

In aviation industry, English skill is prominent for any airport personnel (Ragan, 1997). To preserve this, PT. Angkasa Pura, the biggest airport operator in Indonesia, employ TOEFL ${ }^{\circledR}$ as an instrument in recruiting new employee. Indonesian Civil Aviation Institute (ICAI), an aviation vocational college had prepared for this situation. ICAI had inserted TOEFL ${ }^{\circledR}$ preparation in the curriculum of all study program including Airport Electrical Engineering (AEE). The objective was students gain 500 of TOEFL score at the end of the program.

However, the learning design was quite different compared to the common Test Preparation Program (TPP) in other institutions or private courses. While TPP generally use 1:5 until 1:8 for teacher - students ratio, ICAI only employ one teacher to manage the whole class which could be consisted of 24 students. The other challenge of this TPP was the varied proficiency of those 24 students' English initial skill since there was no selection or grouping in enrolling the class.

Khati in Manuel (2015) said that determining a class as large multilevel students was depending on the context. Aoumeur (2017) also validated that teaching and learning can be altered by class size in various manners. Bell (2004) brought up that learner in a multilevel class are not split only by their proficiency of English language. This TOEFL ${ }^{\circledR}$ preparation in ICAI could be classified as large multilevel class viewed from the number and the initial skill of students, and also the learning objective. There was same objective for the whole students that is passing 500 on TOEFL score. They have different initial skills but have the same period of learning in TOEFL preparation class.

To manage this problem, the English teacher had to arrange a strategy to cope with this large multilevel classroom problem.

Previously, Ashton (2019) examined approaches in teaching a multi-level language classroom. This study was undertaken in a school context. It then suggested another study in larger language 
learning contexts where greater variability of students commonly exist. Hence, this study attempts to analyze strategy in teaching multi-level classroom in university context.

This study attempted to investigate the strategy used by a teacher in giving TOEFL preparation of a class in ICAI. Factors influenced the implementation of the strategy were explained to gain complete understanding toward the issue. Hopefully, this study could be a consideration in developing strategy or learning design in coping similar problem of large-multilevel class in English learning.

There are various perceptions whether a class classified as large or small relying on from context to context. Thus, definition of large class could not be standardized (Manuel, 2015). In accordance, $\mathrm{Ur}$ (2013) stated that "Large is of course, a relative term and what a 'large class' is will vary from place to place". Regardless of the exact number of the students in it, a class could still be measured as large one. It depends on the teacher recognition toward the explicit condition. Though, 40-50 student was large class. When the teacher is no longer acquainted and cope with a number of students, a class was constituted as large.

Writers had different interpretation about the word multilevel. Some writers such as Gurgenidze (2012) and Ur (2019) explained this kind of class using the term "mixed ability classes".

Mathews-Aydinli \& Horne (2006) specified that "typically, the label multilevel has come to describe classes where students from various levels, from beginning to advanced, are sited together in a single class". Gurgenidze (2012) concerned mixed ability class on this multi level issue in another way:" mixed ability level teaching is related to working together with students who have different personalities, skills, interests and learning needs". The ideas were restated in a sole delineation form by Khati (2011) appropriately, a large class has many learners and a multilevel class has learners of wide range of levels or differences. Students in this type of classes have a lot of differences. For example, there are differences on language learning ability, cultural background, learning style, age, attitude to the language, mother tongue, learning experience, and motivational orientation.

Entirely, the definitions above became feasible concern to reach at this point and conclude that a Large and Multilevel Class is a classroom estimated with numerous range / abilities of students (from beginner to advanced/skillful with less skillful) who have the opportunity to learn together in that single class. The entire descriptions above are valuables to comprehend understanding about the problem being examined. Nevertheless, to attain the purpose of the research, the explanation presented by Khati (2011)was the most suitable with this study. The complete aspects related to the term/definition being discussed was embodied in this definition. On the other hand, a great deal of strategies from the teacher are needed to teach this kind of classes. Hence, the challenges evolved throughout the learning process may be dealt entirely.

Bell (2004) brought up that learner in a multilevel class are not split only by their proficiency of English language. The learners' past involvement in training should be counted also. Their nation and culture of source, their individual contrasts, for example, age, knowledge and inspiration, and their specific learning circumstances are example of these factors. Teacher may use many kinds of approach to cope with these diverse and significant aspects. Exploring the issues that teacher may confront would be motivating and demanding report. Grouping Strategies Jong et al. (2006) affirmed that opportunity for observing learners' condition was hardly had in classroom environments with huge number of learners. Consequently, learners who learn fast systematically comprehend the subject, while learners who absorb slowly drop further and further behind until, in some cases, the learning system yield on them completely. Jong then proposed a grouping scheme that are further explained: While learning is ongoing, learners' improvement is checked, just like the state of the groups. Thus, before learning finish, the most recent state of the whole groups must be inspected intermittently, and groups with difficulties must be accommodated. The inactive groups are then rearranged and, at the same time, proper groups are preserved.

\section{METHODS}

This study attempted to explore the strategy used by English teacher in ICAI in managing TOEFL Preparation. The challenge occurred when there was an objective that each student who had various 


\section{Benny Kurnianto}

initial skills/level had to gain 500 of TOEFL score at the end of the program. The teacher needed to develop strategy to manage this kind of program which normally undertaken phase by phase for each level.

To gain precise exploration, this study took a class in ICAI carrying out TOEFL Preparation in two semester, TBL 17. This class could represent general condition of TOEFL Preparation which put in the curriculum and had course name Advanced English 1 and Advanced English 2.

The study was begun by giving the students a pre-test to measure each student initial level. The form of pre-test was similar to real TOEFL test which consist of Listening, Structure and Reading.

The result of this pre-test would later also be used to measure the improvement of each students and the whole class. Consequently, this study also prepared a post-test. Both tests would then be compared at later stage.

From the result of the pre-test, 3 criteria of students were made: 1 ) students gain score $\geq 500$, 2) students gain score 400-499, and 3) students gain score $<400$. It was then transferred into a diagram to see the composition of student's level in the classroom. It was assumed that students who gain below 400 were actually need two phases of TPP to meet the objective of learning. Then, students who gain below 500 were assumed that they need one phase of TPP to meet the objective of learning. TLB 17 had 50 hours in 16 meeting in one semester. Since, this class had Advanced English in 2 semesters, this study had opportunity to have in class observation for 100 hours in 32 meetings.

On the first 5 meetings, the observation focuses on finding: 1) the students' response that show difficulty in understanding the teacher explanation, and 2) the students' response that show satisfaction in understanding the teacher explanation.

The response could be seen from student's expression after listening to explanation. To validate this expression, students were given further question orally according to the material explained. They were then asked to analyze TOEFL question according to the latest discussion.

While observing, the teacher tag students and make 3 group criteria i.e. slower students - students that show difficulty response, faster student - students that show easiness in understanding explanation, and average student - students that were not belong to two previous group. On the next 5 meetings, grouping strategy observation was began. In the first phase, students were asked to sit in groups of 4 . The separation took in traditional manner. Observation was taken that focus on considering group performance and each member of the group achievement. Another tagging was made to separate inactive and active groups. Inactive groups were then given intensive guidance in understanding the material. Another observation was made to indicate the individual performance in those groups. It would explore the performance of slower students in inactive group.

The active groups were then investigated to explore the faster learner's performance in the groups. New grouping arrangement were then settled in the rest meetings. A modification was made where students were asked to sit in groups without perimeter. Students could sit to any companion, but it was enforced that each group had responsibility to made each member understand the material given in same manner. The students who show difficulty in the groups were given groups guidance. The faster students in that group were enforced to assist the slower ones. When the assistance was not working in a particular group or it was found inactive group, the teacher would rearrange the groups on the following meeting. The slower students in each group were also enforced to utter their analysis. The other member of group was enforced to give comment and improvement.

The whole observation was written as accurate as possible. Any form of response from both students and teacher became valuable data. The effect occurred toward slower students and faster students during both kind of grouping process were investigated and then interpreted its relation.

The performance of slower students was compared when they were in in-perimeter grouping and when they were in non-perimeter grouping. The achievement of faster students who gave assistance were also examined.

At the end of program, students were given a post test. The result of post-test was compared to the result of pre-test to see student's improvement individually and collectively. Both the results of pre-test and post test were transferred into table to make easier to interpret. The interpretation was 
then made toward the grouping strategy implemented by the teacher and suggestion for another topic to complete research.

\section{RESULTS AND DISCUSSION}

There was an issue brought in this study. Most industry that absorbed the graduates of ICAI, such as PT Angkasa Pura, required that the candidates had to pass score 500 of TOEFL. It means that English skill requirement was at least on advanced level. Basically, a new curriculum had been applied at STPI since 2016. TLB 17, one of the study programs in this higher education, got a kind of TOEFL preparation for two semesters. It means that this class learn the material for around 100 hours in a year.

The frequency of course was one meeting per week. The effective time was 3 hours per meeting. A teacher attended for each meeting to teach this class which is consisted of 21 students. Although the program was started with various level of students, after passing through approximately 100 hours this 'special' course, the student gained interesting result.

Hence, this report was written to explore factors that influenced the course and explain how the teacher coped with them. The study was begun by giving a pre-test to TBL 17 . The result of the test showed that $81 \%$ of the students in the class obtained score less than 400 and $19 \%$ of the students attained score between 400 - 500. It means that no one gained score more than 500 .

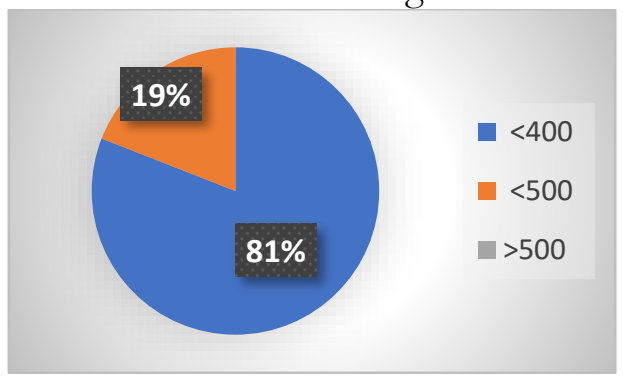

Diagram 1. Pre-Test TOEFL result

From this data, it could be perceived that that skill level of the students was varied and the teacher need strategy to cope with this kind of class.

\section{Cost Effective Policy}

The teacher had to arrange strategy in class since the management had its own decision in concern to the issue. From the program design, the course was treated similar as the other course as usual. 21 varied students in a class was taught by a single English teacher. Material was given once week for the whole semester. This identical program was completed for two semesters but interrupted by internship program for one year. Therefore, the class gained course 2 x 50 hours intermittently.

The management gave no prescription to the material taken in the program. Thus, the teacher had adopted and developed material from Longman TOEFL Preparation. The goal of this material would be accomplished when students had completely read 687 pages of the book.

\section{Identified Factors and The Strategy}

Based on those limitations, a strategy was arranged by the teacher to cope with the situation. Several factors had become apprehension in developing strategy. Therefore, this study attempted to seeks and analyze the factors identified during the learning process and the conformity to the strategy taken in managing this kind of class.

\section{First Factor: Ratio of teacher and students}

A teacher stood among 21 students in a class become a cliché condition found in this class. Correspondingly, academics argued that learners' success and performance had a direct correlation with the quantity of students in a classroom. Large number of learners in classroom have destructive effect on learners' attitude, achievement, and voluntary participation (Achilles \& Finn, 2006).

On the case study of TLB 17, the teacher identified some challenge in the early meetings:

1. The teacher felt hard to observe the student learning progress individually. With 21 students in the class, the teacher only focused to students who gave direct response along the learning 


\section{Benny Kurnianto}

process. For example, only several motivated students gave question as soon as they were confused with the material delivered. However, the teacher did not give time to check all students' understanding since there was weekly target of material to be completed.

2. The teacher felt difficult to control the whole students' activities. There were motivated students that demand a faster learning rhythm. At the same time, there were other slower students. These diverse learning speed made the class management was not trouble-free. When the teacher followed the faster group speed, the slower group looked giving up and did another activity with their own laptop. However, when the teacher kept on the slower group speed, the other motivated students would give a kind of tension. For example, when the teacher gave question to discuss with a slower student, another faster student would take the turn and answer the question quickly.

3. Both faster and slower students in this class revealed disruptive behavior, and the teacher got a challenge spending more time on discipline, placing less time for material discussion. I the early meetings, the teachers found difficulty to diagnose and track student learning and finally give the same instruction for the whole students. In this class students spend more time offtask or disengaged from the work of the class. In this class, students were not able to demonstrate their capacity to adjust to academic and educational tasks.

4. Second Factor: wide range of level. The label multilevel has been regarded differently among researchers. Namely, while some call multilevel, others such as Gurgenidze (2012), Ur (2019) and others tend to call them "mixed ability classes" when citing to these types of classes.

On the case of TLB 17, the class identified as multilevel class where students from a wide range of levels, from beginning to advanced, were placed together in a single classroom. This assumption was validated through the result of the pre-test. It shows that $19 \%$ of student gain score in the range 400-499. These students were considered in intermediate level and acceptable to meet the objective passing advance in one phase. However, there were 81 students that were considered in various level below intermediate. A multilevel class condition had become the second challenge for the teacher.

\section{Cooperative and flexible grouping}

Manitoba Education and Youth (2003) argued that learning in a multilevel classroom is frequently achieved within a workshop design that employs a variety of groupings and allows the multilevel teacher to teach "individually all at once." In more comprehensive steps, Manitoba Education and Youth recommends that teachers could employ an "hourglass" model for workshops, following these stages:

1. Stage 1: Whole-class setting for reflection, planning, and initial instruction

2. Stage 2: Cooperative and flexible groups to prepare for learning

3. Stage 3: Flexible group(s) for strategic instruction, guided practice, and/or conferences

4. Stage 4: Cooperative and flexible groups to practice and apply learning

5. Stage 5: Whole-class setting for sharing, reflection, goal setting, and further planning

Dividing the class and adding teacher would not be the first-line option since it would discord the management policy which had difficulty in preparing the classroom and time. However, the teacher had an objective to increase those various initial skill students to gain minimum required score in predetermined time.

The first consideration taken was driving all those students to learn in one phase since the teacher had a target to finish the material on schedule. On the early meeting, a lot of students showed difficulty in understanding the teacher's explanation individually. However, some students looked comfortable with the phase. Here, it was found that in this classroom there were much more slower learner than faster learner.

On the following meetings, the teacher began to arrange the class into several group consisting of 4-5 students. However, on several meetings most slower students sat with other slower students and faster students sat with faster learner. Each group were asked to analyze question and shared the result of their discussion. Here, it was found that most group became inactive group. Though there were lively speaker in some group representing the analysis, the group discussion did not run well. 
Here, it was found that there were active and inactive group. To overcome the problem, the teacher modified the groups arrangement. Before dividing the students into groups, the teacher enforced students by giving a goal. After explaining the material, teacher asked student to discuss their analysis in solving TOEFL question. Each member of the group should deliver their analysis in front of the group, and the other members should give feedback should there were any inaccuracy. Then, in turn a representative of the groups were asked to deliver their analysis to the class.

The teacher gave reminder to the groups that the purpose of the task was not choosing answer from multiple option, but it was explaining the steps to get into the answer. Then, students were asked to sit in group. This time, the teacher give freedom for student to arrange the groups. There were no more limitation of the number of group and group member. Unpredictably, the slower students moved approaching the faster students. Afterwards, the group discussion was working lively.

Inactive group still occurred. However, the teacher could give intensive guidance and trigger this group to have discussion in their own group or even with another group.

\section{Code mixing}

The biggest challenge in teaching TLB 17 is that this class consist of students with multilevel initial skill. However, the teacher had an objective to make all student have at least the same level at the end of the TOEFL preparation program. It means that teacher have to accelerate the lowest level student to complete advanced level in limited time. Therefore, the teacher decided to deliver the explanation not entirely in English. This was another strategy that is used by the teacher to transfer the explanation in the book into simpler language that could be understood by all the students.

The use of L1 (first language) in EFL (English as a Foreign Language) learning is still debatable. Puspawati (2018) argued that Codes Switching is not an escape for teachers whose language proficiency is low, but it is a teaching and learning facilities when it is used correctly and appropriately can help students learn better and help teachers teach more effectively.

Since the range of the student's levels was wide, the teacher chose to frequently switch to L1 in explaining material. This decision was made considering that there were $81 \%$ student measured not passing intermediate level (scored below 400).

The teacher had another consideration. The explanation in the book was regarded quite difficult for the students in such level. Therefore, the teacher developed simpler material suitable with Indonesian learner. Before discussing the explanation from the book, a foundation of English grammar according the theory of syntax was given. Hence, students had focused on the sentence structure that consist of 3 kind of phrase i.e noun phrase, verb phrase and preposition phrase. It was in accordance to the explanation in Longman book that the root in analyzing the sentence is finding the set or sets of subject and verb in each sentence.

\section{Impact of the Strategy}

The outcome of the strategies could be measured in the result of the simulation test. This simulation was conducted under idyllic condition as required by TOEFL.

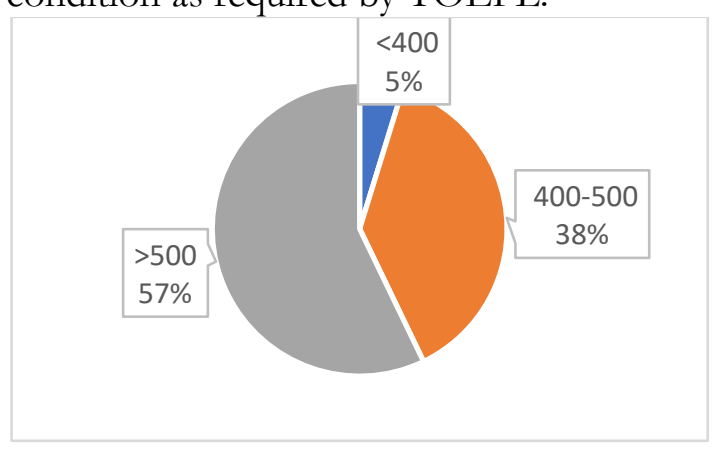

Diagram 2. Post Test Result

Compared to pretest result, student made significant improvement. On average, the rising score was 133 point. From 21 students in the class, one person did not reach 400, 12 students were able to pass 500, and 8 students gained between 400- 500. It showed that implementation of the strategy succeeded in assisting 12 students achieved the learning objective. This result could be consideration 


\section{Benny Kurnianto}

in changing the learning design. Hunt et al. (2013) pronounced that class proportion was a main aspect in learner development. There might some consideration for organization to decide policy in several manner.

Designating teachers to manage more classes with smaller number of learners in every class does not signify a decrease in workload. If, a lot of student were placed in a single class but did not complete a course, there would be a shifting ratio of class proportion to job assignment.

Though it needs more examination to recognize the complete consequence of class size, the research shows that only fast learner and highly motivated students were able express their ability. Whereas slower learner suffered from the highest-level determination. On the pre-test, multiple choice was mistreated to measured students' former skills. Teacher needs to assess students' skills in analyzing multiple choice questions of TOEFL in a written essay. This assessment would be more reliable in grouping the students. The upshots of decreasing class size should be evaluated with several instruments.

\section{CONCLUSION}

Though this study had boundary to analyze the capacity of the students and the teacher, the result shows that both factors was quite significant. The teacher considered that 24 students in a single class was too large, thus grouping strategy was taken. Since the teacher also recognized that the skill of students was varied, a modification on grouping strategy was taken to overcome multi level skill hindrance.

It was found that with consistent enforcement, both slower students and faster students showed positive improvement. Though they started the program with various skill, at the end of the program they could demonstrate that both groups make enhancement with slight difference.

It could be taken advantage the existence of faster students to give assistance to slower student. Conversely, the slower student understanding could be an objective for faster students in explaining precise analysis. Thus, required two phases program could be undertaken in one phase.

This case study confirmed that only 12 from 21 student succeeded passing 500 . Though it needed further research, the test result showed that a class with a single English teacher managing 21 students was regarded large. Further research could be conducted by minimizing the number of students in class.

\section{REFERENCES}

Achilles, C. M., \& Finn, J. D. (2006). Education Administration Professor's Role to Assure that Preparation Programs Address Validity and Critique Skills. UNBRIDLED SPIRIT: Best Practices in Educational Administration, 257.

Aoumeur, H. (2017). The Impact of Class Size on Teaching and Learning English as a Foreign Language: The Case of the Department of English at Abdelhamid Ibn Badis University. Arab World English Journal, 8(2), 349-361. https://doi.org/10.24093/awej/vol8no2.25

Ashton, K. (2019). Approaches to teaching in the multi-level language classroom. Innovation in Language Learning and Teaching, 13(2), 162-177.

https://doi.org/10.1080/17501229.2017.1397158

Bell, J. (2004). Teaching multilevel classes in ESL. Pippin Pub.

Gurgenidze, M. (2012). Methodology : Teaching Mixed Ability Classes. 1(1), 56-63.

Hunt, T., Carper, J., Lasley, T., Raisch, C., \& Bowman, C. L. (2013). National Council of Teachers of English. In Encyclopedia of Educational Reform and Dissent. https://doi.org/10.4135/9781412957403.n296

Jong, B., Wu, Y., \& Chan, T. (2006). Dynamic grouping strategies based on a conceptual graph for cooperative learning. IEEE Transactions on Knowledge and Data Engineering, 18(6), 738-747.

Khati, A. R. (2011). Contribution of Teacher to Learner Motivation in EFL. Journal of NELTA. https://doi.org/10.3126/nelta.v13i1-2.4637

Manitoba Education and Youth. (2003). Independent Together Supporting the Multilevel Learning 
Community.

Manuel, J. K. (2015). Strategies Used to Teach a Large Multilevel Class. Instituto Superior de Ciências Da Educação ISCED - HUÍL A Departamento de Letras Modernas Repartição de Inglês.

Mathews-Aydinli, J., \& Horne, R. Van. (2006). Promoting Success of Multilevel ESL Classes: What Teachers and Administrators Can Do. CAELA Brief.

Peter H. Ragan. (1997). Aviation English: An Introduction. Journal of Aviation/Aerospace Education \& Research, 7(2).

Puspawati, I. (2018). Teachers' Use of Code Switching in EFL Classroom and its Functions. Journal of Foreign Language Teaching and Learning, 3(1), 42-51.

Ur, P. (2013). Language-teaching method revisited. ELT Journal. https://doi.org/10.1093/elt/cct041

Ur, P. (2019). Theory and practice in language teacher education. Language Teaching.

https://doi.org/10.1017/S0261444819000090 